\title{
AGENCIAS ANTICORRUPÇÃO E ADMINISTRAÇÃO PÚBLICA: UMA PERSPECTIVA COMPARADA ENTRE O BRASIL E OUTROS PAÍSES
}

\author{
Luciano Vaz Ferreira ${ }^{1}$ \\ Mateus de Oliveira Fornasier ${ }^{2}$
}

\section{Resumo}

Este artigo visa realizar caracterizar e comparar várias maneiras pelas quais se tem buscado evitar e perseguir a corrupção pública em vários países. Seu problema de pesquisa foi: sob que condições o conhecimento produzido acerca da corrupção na esfera pública (sobre agências anticorrupção, principalmente) pode fomentar melhores atuações para os órgãos e entes da Administração Pública disso ocupadas? Sua hipótese aponta que o estudo dos modelos anticorrupção utilizados por diversos países, em seus contextos histórico-geográficos e institucionais específicos, pode ser útil para a renovação e reestruturação dos sistemas jurídico e político brasileiros nesta área.

Palavras-chave: corrupção pública; agências anticorrupção; Administração Pública.

\section{INTRODUÇÃO}

Este artigo visa realizar uma caracterização, em perspectiva comparada, dos modos pelos quais vários países têm se ocupado da regulamentação da persecução à corrupção pública. Nesta senda, teve como problema de pesquisa o seguinte questionamento: sob que condições o conhecimento produzido acerca da corrupção na esfera pública - principalmente no que tange à instituição de agências anticorrupção - pode vir a fomentar reflexivamente, no Brasil, melhores atividades para os órgãos e entes da Administração Pública que aqui se ocupam da mesma função? Sua hipótese aponta que o estudo dos modelos anticorrupção utilizados por diversos países, em seus contextos histórico-geográficos e institucionais específicos, pode ser útil para a renovação e reestruturação do sistema jurídico-político brasileiro nesta área. Há teorias que formulam conceitos bastante amplos de corrupção, como a teoria dos sistemas autopoiéticos, por exemplo. Neste contexto, a corrupção seria uma ocorrência de acordo com a qual um sistema funcional da sociedade sobreporia sua lógica ao funcionamento

\footnotetext{
${ }^{1}$ Doutor em Estudos Estratégicos Internacionais (UFRGS). Professor da Universidade Federal do Rio Grande (FURG). E-mail: lvazferreira@gmail.com

${ }^{2}$ Doutor em Direito Público pela Universidade do Vale do Rio dos Sinos (UNISINOS). Professor do Mestrado em Direitos Humanos da Universidade Regional do Noroeste do Estado do Rio Grande do Sul (UNIJUí). E-mail: mateus.fornasier@unijui.edu.br 
de outro sistema funcional da sociedade (LUHMANN, 2007, p. 262; NEVES, 2009, p. 42-43). Um sistema funcional destinado a decidir acerca de expectativas normativas generalizadas em sociedade (e.g. a política, que opera a partir da lógica "oposição/situação") realizaria decisões com base em códigos binários pertencentes a outros sistemas, tais como o da economia (o qual se embasa na lógica "pagamento/não pagamento"). Em síntese, ter-se-ia a compra (ou venda) de votos a fim de se obter determinada vantagem. Contudo, não se observaria o fenômeno apenas quando o código econômico se sobrepõe aos demais: qualquer sobreposição de lógica sistêmica significaria uma corrupção (e.g. a decisão jurídica que se embasa na lógica religiosa ao arrepio da lei; etc.).

No presente texto, contudo, não se tratará da corrupção no seu sentido sistêmico. Vai-se, isto sim, abordar o problema da corrupção pública, a qual poderá ser caracterizada como o abuso de cargo público para obter benefícios privados. Bobbio, Matteucci e Pasquino (1998, p. 291) a caracterizam como o "fenômeno pelo qual um funcionário público é levado a agir de modo diverso dos padrões normativos do sistema, favorecendo interesses particulares em troca de recompensa". Em sentido similar, Shleifer e Vishny (1998, p. 599) a caracterizam como a "venda" da propriedade pública por oficiais governamentais para a percepção de ganho pessoal, que pode incluir sua família, amigos, partido político, classe social ou comunidade (TANZI, 1998, p. 564). É possível classificá-la em "corrupção burocrática” e "corrupção política” (ELLIOTT, 2002, p. 260).

A corrupção burocrática nasce da interação entre servidores públicos de escalão inferior e os cidadãos em geral. Podem ser classificados como corrupção política as ações cometidas na alta hierarquia do governo que distorcem políticas públicas ou o funcionamento central do Estado, permitindo que esses líderes se beneficiem à custas do patrimônio público. Esta modalidade de corrupção é comumente associada à ideia de "cleptocracia", "quando líderes políticos, geralmente autocratas sem qualquer controle por um sistema de freios e contrapesos abertamente usam as instituições para enriquecerem de qualquer maneira possível” (MANZETTI; WILSON, 2009, p. 80).

É possível dividir a corrupção pública em quatro tipos de atos: apropriação indébita, patronagem, suborno e abuso de funções. A primeira é a apropriação (desvio ou malversação) indevida (indébita) de recursos de proveito econômico. A patronagem é a seleção de pessoa para um emprego ou benefício governamental levando em consideração apenas os seus vínculos políticos e demais conexões, em detrimento da qualificação ou titulação. O suborno pode ser caracterizado como o uso de um incentivo para influenciar indevidamente o desempenho de pessoa que exerce função pública (NYE, 1967, p. 419; NOONAN JUNIOR, 1989, p. xi; BOBBIO; MATTEUCCI; PASQUINO, 1998, p. 291). O abuso de funções ocorre quando alguém viola seus deveres funcionais em favor do proveito próprio. 
Adotou-se, para a elaboração deste trabalho, uma metodologia analítico-comparativa, a partir da consecução de uma pesquisa bibliográfica e documental. A fim de concretizar o objetivo geral deste artigo, estabeleceu-se sua divisão em três específicos, cada qual expresso em uma subdivisão peculiar do seu desenvolvimento. A primeira parte busca traçar um panorama geral acerca daquilo que se entende como corrupção por vários autores, de modo a delinear um conceito a ser utilizado na pesquisa. Já em sua segunda subdivisão, este texto descreve várias experiências estatais e internacionais de persecução às práticas corruptas que venham a afetar a Administração Pública. Por fim, o terceiro momento do desenvolvimento deste texto descreve de que modo as agências anticorrupção são institucionalizadas e normatizadas no Brasil e apresenta uma série de proposições para o melhor funcionamento destas estruturas no contexto brasileiro, com suporte no estudo comparativo realizado.

\section{O FENÔMENO DA CORRUPÇÃO: UMA BREVE HISTÓRIA DA(S) TEORIA(S)}

Até a década de 1990 não havia uma percepção muito clara sobre os malefícios da corrupção no mundo. O fenômeno era encarado como um problema típico de sociedades periféricas, marcadas pela origem colonial, clientelismo e predominância das relações familiares, confusão entre o público e o privado, e instituições democráticas jovens (TULCHIN; ESPACH, 2000, p. 10). No contexto de Guerra Fria, os círculos acadêmicos, tradicionalmente dominados por norte-americanos e europeus, evitavam tecer críticas a regimes cleptocráticos, muitos aliados do bloco ocidental (MORRIS; BLAKE, 2009, p. 05). Chegou-se a defender, de maneira absurda, que a corrupção era benéfica aos países em desenvolvimento (LEFF, 1964; HUNTINGTON, 1968), pois ajudaria a superar os entraves burocráticos na tomada de decisões governamentais.

A globalização e o fim da Guerra Fria foram fundamentais para uma mudança de postura que colocou o controle da corrupção como um dos grandes temas de discussão mundial. A vitória do capitalismo trouxe, ao mesmo tempo, a maior abertura da economia e a propagação de instituições democráticas, baseadas, especialmente, em práticas de transparência. Glynn, Kobrin e Naím (2002, p. 29) apontam uma intensificação, no período pós-90, de uma "crise de legitimidade" na política mundial: desde as mais avançadas democracias até os Estados mais repressivos, "a proporção do poder entre os líderes e a população teria mudado, em favor de uma governança transparente e democrática". O surgimento da chamada "era da informação", graças aos avanços tecnológicos experimentados, é um elemento-chave, uma vez que o acesso facilitado à informação conduz ao clamor público pela transparência e detalhamento das ações governamentais. O impacto do desvelamento dos casos de corrupção tornou-se instantâneo, devido ao alcance da via informacional.

O fim da Guerra Fria passa, assim, a expor a impossibilidade de apoio às cleptocracias. Os países periféricos foram objeto de grandes mudanças e a corrupção passou a ser vista como um obstáculo para o 
desenvolvimento destas regiões. O golpe de misericórdia ocorreu quando uma série de escândalos de corrupção envolvendo países europeus (como França, Itália, Alemanha e Reino Unido) e asiáticos (Japão), antes tidos como imaculados, foi noticiada na década de 90 . Logo, a corrupção não era mais um problema apenas de terras longínquas e atrasadas culturalmente, mas uma preocupação doméstica nestes países.

Hoje, a corrupção é encarada como uma ameaça tanto para os países em via de democratização quanto para as democracias modernas (SPECK, 2002, 446). De acordo com trabalho da ONG Transparency International, entre 114.000 pessoas entrevistas em 107 países, 1 a cada 4 entrevistados admitiu ter pago suborno em alguma ocasião (TRANSPARENCY INTERNATIONAL, 2013, p. 10). Kaufmann (1999) estima que cerca de 1 trilhão de dólares são pagos em suborno anualmente no mundo. Pesquisas relacionam a corrupção ao baixo crescimento econômico (MAURO, 1995, p. 705); à evasão fiscal e graves prejuízos orçamentários estatais (MAURO, 2002, p. 141); à diminuição da confiança pública na democracia (TANZI, 1998, p. 583); aos gastos públicos ineficientes (SHLEIFER; VISHNY, 1993, p. 616); às distorções concorrenciais em licitações (HEIMANN, 2002, p. 220); ao decréscimo de investimento estrangeiro direto (WEI, 2001, p. 01-02).

Vários são os trabalhos - já considerados clássicos - que se apegam ao tema da origem da corrupção no Brasil. Raymundo Faoro (2001) atribui o fenômeno à herança política da colonização portuguesa, que conduziu à caracterização da política brasileira como patrimonialista e praticada por um estamento, classe política organizada em torno dos seus próprios interesses. Victor Nunes Leal (1997), ao tratar do fenômeno do coronelismo, deixa transparecer que a obtenção de vantagens eleitorais por aqueles que detêm renda e terras decorre, principalmente, da concentração da propriedade fundiária rural, da desorganização do serviço público em prol da população e de uma resultante relação de dependência pessoal entre aqueles e os menos favorecidos. Roberto DaMatta (1986, p. 119), por seu turno, atribui às relações humanas no Brasil uma lógica relacional:

Que na política aparece com o nome de negociação e conciliação. Que no mundo econômico surge na curiosa combinação de uma economia altamente estatizada com uma iniciativa privada vigorosa e ainda importante. Que na religião aparece com a intrigante mistura de catolicismo com religiões afro-populares. E que na cosmologia em geral [...] aparece sob uma certa ânsia de criar personagens intermediários, gente que pode permitir a conciliação de tudo o que a sociedade mantém irremediavelmente dividido por um movimento inconsciente.

Em que pese a importância destes trabalhos em buscar a justificativa histórica da corrupção no Brasil, não se pode acreditar que apenas em países que passaram por um processo de colonização de exploração apresentem em suas redes de relação sociopolítica e econômica a ocorrência da corrupção. Esta não deve ser vista como uma "herança maldita" de países em desenvolvimento. O discurso do determinismo cultural esquece, proposital mente, o histórico da corrupção em sociedades modernas (como a europeia e a norte-americana) e o desenvolvimento de certas condições estruturais positivas em países como o Brasil nos últimos anos, como o processo de 
democratização, a diminuição da pobreza e a maior inclusão no sistema educacional (TAYLOR; POWER, 201 1, p. 11).

O fenômeno da corrupção deve ser visto como uma consequência natural da interação entre os interesses públicos e privados nas estruturas governamentais. Conforme Rose-Ackerman (2002, p. 59), práticas corruptas encontram um ambiente propício para serem bem sucedidas sempre que uma autoridade pública exerce seu poder discricionário sobre a distribuição de um benefício ou de um custo para o setor privado. Sabe-se que o Estado possui o poder de comprar e vender bens e serviços, oferecer concessões e distribuir subsídios (benefícios), bem como arrecadar impostos, impor regulamentações e exigir autorizações (custos). Do outro lado, existe um setor privado dotado de poder econômico e disposto a pagar para ter acesso a esses benefícios ou reduzir os custos que foram impostos. Como todas as atividades mencionadas são inerentes ao funcionamento dos governos contemporâneos, a criação de incentivos para a corrupção é um fato inevitável.

O modelo "dirigente-agente-cliente", proposto por Klitgaard (1994, p. 83), ajuda a compreender a dinâmica da corrupção. O "dirigente" pode ser representado como o oficial de hierarquia superior dentro da administração pública; o "agente” como funcionário de hierarquia inferior e responsável por manter contato com o "cliente"; o "cliente" como a parte representando o setor privado. Todos possuem interesses e comportamentos independentes. O dirigente responsável por implementar uma política anticorrupção em seu governo deve saber que o "agente", apesar de inserido na estrutura estatal, faz seus próprios cálculos com objetivo de mensurar os lucros de aceitar um possível suborno e os prováveis custos de ser identificado e punido. Da mesma maneira, o "cliente" será compelido a tentar corromper o "agente" público com o objetivo de obter benefícios ou afastar custos, desde que não seja capaz de vislumbrar a possibilidade de punição. Nesta linha, a corrupção é vista como uma questão de oportunidade (KLITGAARD, MACLEAN-ABAROA; PARRIS, 2000, p. 27).

A alteração deste sistema só é possível por meio de reformas institucionais. Douglass North (1991, p. 97) conceitua as instituições como restrições à conduta humana desenvolvidas para estruturar as interações políticas, econômicas e sociais da vida em sociedade. Consistem em restrições informais (como costumes e códigos de condutas) e regras formais (como o sistema jurídico). O comportamento egoístico e utilitarista dos atores econômicos e sociais é claramente influenciado pela configuração das instituições nacionais, estrangeiras e internacionais. Neste contexto, entende-se que a criação e alteração de normas jurídicas (internas e internacionais) são capazes de mudar o ambiente institucional e interferir diretamente no comportamento dos agentes e clientes. A cautela é necessária na escolha das possíveis reformas, uma vez que a agenda anticorrupção, conforme Kennedy (1999, p. 461), pode ser um pretexto para inserção de uma série de receitas carregadas de forte conteúdo ideológico, como no caso do uso da desregulamentação e da privatização como medidas de enfrentamento da corrupção, estratégias altamente contestáveis. 


\section{AGENCIAS ANTICORRUPÇÃO: DESENVOLVIMENTO NO PANORAMA INTERNACIONAL}

É comum os Estados sentirem-se compelidos a especializarem parte de suas estruturas, objetivando um maior planejamento e cuidado com uma determinada política pública, como saúde, educação e segurança. Nas últimas décadas, tal processo também ocorreu com as políticas anticorrupção, que passaram a ser geridas, em muitos países, por órgãos especializados, dotados de conhecimento necessário e relativa autonomia para promoverem a prevenção e controle do problema. A criação destas entidades - conhecidas como "agências anticorrupção" - pode representar um passo importante nas mudanças institucionais necessárias para a interferência nos incentivos às práticas corruptas.

Sousa (2008, p. 23) conceitua as agências anticorrupção como "um órgão (de financiamento) público e de natureza durável, com uma missão específica de combate à corrupção e de redução das estruturas de oportunidade propícias para a sua ocorrência através de estratégias de prevenção e repressão". Sua origem reportase ao processo de descolonização do pós-Segunda Guerra Mundial (1945) no continente asiático. O Reino Unido, com histórica presença na região, auxiliou na criação destas instituições em algumas de suas ex-colônias, como tentativa de "limpar" a reputação das antigas administrações coloniais, conhecidas pela corrupção desenfreada, e desenvolver novos governos, recém-independentes, dentro de um contexto de autodeterminação, livres de antigos hábitos (SOUSA, 2010, p. 06). As primeiras agências foram criadas em Singapura (1952), Malásia (1967) e Hong Kong (1974), com resultados surpreendentes. No fim da década de 80 e início dos anos 90, quando o controle da corrupção tornou-se prioridade governamental na agenda de vários países, o modelo difundiu-se fora da Ásia, na Austrália (1988), Malta (1988), República Checa (1991), França (1993) e Botsuana (1994). Por fim, a expansão da União Europeia para o Leste nos últimos anos do século XX também influenciou muitos Estados da região a reformarem sua estrutura política e criarem órgãos anticorrupção, como é o caso da Lituânia (1997), Croácia (2001), Letônia (2002) e Romênia (2002).

Hoje estas experiências têm sido difundidas globalmente. A Convenção Interamericana contra a Corrupção, de 1997, e a Convenção das Nações Unidas contra a Corrupção, de 2003, estabelecem a obrigatoriedade da criação de agências anticorrupção entre os Estados-membros (art. III, 9 da Convenção da OEA e art. $6^{\circ}$ e 36 da Convenção da ONU), conduzindo à interpretação de que estas entidades devem ocupar um papel de destaque no controle da corrupção, tanto na coordenação das estratégias quanto na possível investigação, processamento e até mesmo penalização destas condutas. 


\section{Configurações de agências anticorrupção}

A implementação de uma agência anticorrupção é claramente um ato simbólico, que representa a reafirmação do compromisso de um governo com a luta contra a corrupção frente a opinião pública (SOUSA, 2010, p. 11). Uma importante vantagem na criação destas organizações está na especialização de suas funções, graças ao foco em um problema único, a corrupção, o que coloca esta estratégia a frente de outras iniciativas que não possuem o suporte de uma estrutura governamental permanente. Sobre este ponto, Speville (2008, p. 04) menciona que a ausência de especialização é uma falta grave comum que acaba fulminando muitas iniciativas. Em órgãos que já possuem funções diversas, como controladorias, ouvidorias, comissões de direitos humanos ou órgãos de gestão de serviços públicos, o controle da corrupção acaba não sendo prioridade nestes mandatos. Sendo assim, o autor defende a necessidade de formar um órgão especializado, capaz de agir como gestor de políticas anticorrupção.

As agências anticorrupção podem apresentar diversas configurações, não havendo um modelo único: centralizadas ou descentralizadas; de caráter preventivo, educacional e informativo ou com poderes de investigação, processamento ou julgamento; ligadas ao poder executivo, legislativo ou judiciário; preocupadas apenas com as condutas dos agentes ou também dos clientes. Sobre este último ponto, observa-se que muitos órgãos não se limitam a promover a ética no setor público e assumem a atribuição de fiscalizarem a conduta de empresas corruptas, nacionais e estrangeiras.

A pesquisa reafirma o movimento de especialização das estruturas estatais no controle do suborno. Em consulta aos sites da ONU (UNODC, 2014), do Banco Mundial (WORLD BANK, 2014) e da Associação Internacional de Autoridades Anticorrupção (INTERNATIONAL ASSOCIATION OF ANTICORRUPTION AUTHORITIES, 2014), descobriu-se que entre 178 países, correspondentes aos signatários da Convenção da ONU contra Corrupção, 124 possuem algum tipo de estrutura anticorrupção especializada, incluindo as iniciativas centralizadas, descentralizadas envolvendo a coordenação de uma série de instituições, e as mais básicas, relacionadas à criação de um departamento especializado dentro da polícia ou da promotoria. Isto corresponde a cerca de $70 \%$ dos Estados-membros do tratado internacional, um número certamente considerável.

Sousa (2008, p. 24-25) classifica as agências anticorrupção em três tipos. As "Instituições com Competências Exclusivamente Preventivas" são aquelas que não possuem poder de sanção, limitando-se apenas a atividades de caráter preventivo, como realizar estudos sobre corrupção de maneira a identificar áreas de risco, aconselhar o poder público para o estabelecimento de estratégias, e servir como intermediador de diferentes órgãos de controle nacionais e internacionais e a sociedade civil. É o caso das agências da França, Macedônia, Albânia, Malta, Bulgária, Montenegro e Índia. 
O segundo modelo explicado por Sousa é denominado "Departamentos Especializados nas Forças Policiais ou Procuradorias". Como o próprio nome diz, possui caráter investigativo e de propositura de ações judiciais em casos de corrupção. Este modelo é adotado na Romênia, Bélgica, Espanha, Portugal, Noruega, Croácia e Hungria.

Por fim, as "Instituições Especializadas com Múltiplas Competências", que congregam, em um único órgão, atividades preventivas, investigativas e repressivas no controle da corrupção e do suborno. Há a possibilidade de manutenção de mecanismos sancionatórios de natureza administrativa. No entanto, é comum nesta modalidade que a função de acusação seja atribuída a uma entidade externa, como o Ministério Público, para evitar a concentração de poderes (OECD, 2008, p. 11). Experiências deste tipo podem ser encontradas em Singapura, Hong Kong, Botsuana, Lituânia, Letônia, Uganda e Argentina.

Apesar de a primeira agência anticorrupção ter sido a de Singapura (Corruption Practices Investigation Bureau) (QUAH, 1995, p. 391), a maioria das iniciativas atuais sofreu uma grande influência da experiência bemsucedida de Hong Kong (POPE; VOGL, 2000, p. 01; SOUSA, 2008, p. 24), que mantém desde 1974 a Independent Comission Against Corruption - ICAC (Comissão Independente Contra a Corrupção). A ilha sofria historicamente com o suborno sistêmico, com destaque para uma força policial extremamente corrupta. A fuga para o exterior de um superintendente-chefe da polícia acusado de corrupção (Peter Godber) foi o estopim para uma série de manifestações populares, que culminaram na discussão sobre a necessidade de reformas institucionais. O resultado foi a criação da Comissão, com as funções não só de receber denúncias de corrupção e investigá-las, mas também de conduzir políticas de conscientização pública e outras estratégias preventivas.

A entidade é dirigida por um Comissário, nomeado pelo Chefe do Poder Executivo de Hong Kong. Divide-se em Departamento de Operações, o maior deles e responsável por receber as denúncias e investigar os casos de corrupção; o Departamento de Prevenção, que possui a atribuição em desenvolver estudos e pesquisa sobre a corrupção, tentando, de maneira preventiva, diminuir a sua ocorrência; o Departamento de Relações Comunitárias, cuja função é desenvolver as políticas de educação sobre o problema direcionadas à comunidade. Uma política anticorrupção sustentada no tripé "investigação, prevenção e educação" é um dos maiores legados da ICAC (DOIG; WATT; WILLIAMS, 2006, p. 163).

À organização foram concedidos poderes especiais para o exercício de seu mandato, que incluem a emissão de ordens de prisão, de requisição de informações, de busca e apreensão e de bloqueio de ativos sem a obrigatoriedade de autorização judicial. Como a organização policial estava comprometida, a Comissão foi pensada como uma entidade independente, submetida apenas a autoridade do Chefe do Poder Executivo. Seu capital humano é interdisciplinar e altamente qualificado, sendo composto por cerca de 1.200 funcionários. O orçamento anual da instituição é de cerca de 85 milhões de dólares (OECD, 2008, p. 46). De modo a evitar uma 
concentração e abuso de poder, a ICAC não possui a função persecutória; isto significa que não é capaz de levar diretamente os casos investigados ao judiciário para condenação, tal atribuição é de discricionariedade da Promotoria. A experiência da Comissão foi considerada, durante muito tempo, como um sucesso: em poucos anos multiplicou o processamento dos casos de corrupção, extraditou Godber e, de maneira mais importante, estabeleceu um laço de admiração e confiança com a sociedade local.

\section{Agências Anticorrupção em Países de Tradição Anglo-Americana}

Enquanto muitos países possuem uma única agência nacional, na Austrália o controle da corrupção desenvolveu-se de maneira regional, com criação de comissões anticorrupção nos Estados, ligadas ao poder legislativo local. A primeira foi a Independent Commission Against Corruption do Estado de New South Wales (1988), visivelmente inspirada na iniciativa de Hong Kong. Nos últimos anos, outros Estados australianos seguiram o exemplo: Queensland (1989), Western Australia (2003), Tasmania (2009), Victoria (2011) e South Australia (2012). Seguindo esta linha, já se discute a possibilidade de criação de uma agência federal australiana.

Os EUA possuem um sistema de controle da corrupção descentralizado e fragmentário, próprio da sua complexa estrutura federativa. O Federal Bureau of Investigations, a polícia federal norte-americana, e o Department of Justice, o ministério da justiça que também possui a função de promotoria pública federal, possuem estruturas especializadas na investigação e processamento da corrupção. Além disso, cada departamento do governo federal (correspondente aos ministérios brasileiros) mantém uma Inspector-General (InspetoriaGeral), que possui a atribuição de investigar casos de corrupção e encaminhar para as autoridades competentes (ANGELI, 2009, p. 83).

Atualmente, os EUA possuem 72 Inspetorias-Gerais. Há ainda o Office of Government Ethics (Escritório de Ética Governamental) entidade do executivo federal que possui apenas a função preventiva de elaborar orientações sobre ética pública aos funcionários federais. É desprovido de qualquer poder investigativo, exercendo um caráter meramente consultivo e educacional (MONTEIRO, 2014, p. 24). No nível local, o mais próximo de uma agência anticorrupção é o Department of Investigations - DOI (Departamento de Investigações) da cidade de Nova Iorque, que possui a função de investigar e encaminhar para a promotoria práticas corruptas realizadas por seus funcionários públicos e atores privados que mantém negócios com o Município. Também de natureza descentralizada são as iniciativas anticorrupção da Suécia e Grécia.

No Reino Unido, há o Serious Fraud Office - SFO (Departamento de Fraudes Graves), criado em 1988. Trata-se de um órgão especializado em casos graves de fraude e corrupção com atuação na Inglaterra, Países de Gales e Irlanda do Norte. O SFO representou uma novidade no sistema jurídico britânico, ao centralizar, no mesmo órgão, os poderes de investigação e acusação, enquanto o padrão adotado reservava, separadamente, à 
polícia a prerrogativa de investigar e ao ministério público de acusar (COEHN; BURRELL; COGMAN, 2010, 24). O SFO é independente e responde apenas ao Procurador-Geral (Attorney General), que é responsável por indicar o seu diretor e fiscalizar suas atividades. Nos últimos anos, tem sido o órgão responsável por aplicar o U.K. Bribery Act, de 201 1, a nova legislação anticorrupção britânica.

\section{REQUISITOS PARA O BOM FUNCIONAMENTO DAS AGENCIAS ANTICORRUPÇÃO E O CONTEXTO BRASILEIRO}

Com base nas experiências de vários países, alguns estudos indicam quais são os elementos indispensáveis para o bom funcionamento de uma agência anticorrupção (SOUSA, 2010, p. 13-18). Primeiro, é importante manter a independência do órgão para executar suas funções. De acordo com Sousa (2008, p. 26), não se trata de irresponsabilidade ou ausência de controle externo à sua atuação, mas a capacidade de poder exercer a sua missão sem interferência política. Sugere-se uma autonomia administrativa e orçamentária, com a garantia de recursos necessários para a realização de suas atividades.

Segundo, as agências anticorrupção não devem agir de maneira solitária, recomendando-se o desenvolvimento de mecanismos de cooperação com outras instituições, nacionais, internacionais e de outros países. Este ponto tem sido considerado como crucial para o sucesso do controle da corrupção pelos Estados, especialmente pela natureza e complexidade das práticas corruptas contemporâneas.

Terceiro, a captação de capital humano especializado e interdisciplinar. Sousa (2010, p. 15) critica o fato de que muitos governos gastam energia nos aspectos formais e legais da criação de suas agências e se preocupam pouco com os recursos humanos, um aspecto fundamental. Ao invés de simplesmente transferir funcionários de outros órgãos como comumente se pratica, a recomendação é no sentido de recrutar e treinar um quadro próprio. O recrutamento deverá ser feito com base no aspecto exclusivamente meritório.

Neste mesmo sentido, a remuneração e os mecanismos de proteção da relação de trabalho devem ser condizentes com a responsabilidade do funcionário. Também tem-se que a seleção do diretor da agência deve ser feita de maneira transparente. Recomenda-se que sua indicação não seja realizada por uma autoridade política de maneira solitária (por exemplo, o Presidente da República), e sim por mais de uma estrutura de poder (como, por exemplo, no caso de indicação do Chefe do Poder Executivo e aprovação pelo Poder Legislativo). Por fim, quanto a esta recomendação, deve existir algum mecanismo de proteção à exoneração da direção por motivos meramente políticos. Uma saída é instituir o exercício da direção por meio de mandatos temporários e estabelecer um procedimento próprio para a sua destituição antes do prazo (OECD, 2008, p. 26). 
Quarto, desenvolver a capacidade de investigar casos complexos e de grande magnitude, como aqueles que envolvem políticos, funcionários de alta hierarquia e grandes empresas, situação que incrementa visibilidade institucional e o apoio público, elementos importantes para sustentar o funcionamento destas agências.

Quinto, funcionar não somente como um órgão sancionatório e disciplinar, mas adotar uma postura preventiva, sendo capaz de, por meio de pesquisa e avaliação de políticas anticorrupção, criar um arcabouço de conhecimento útil para orientar as estratégias no futuro.

Sexto, a manutenção de agência anticorrupção deve ser um projeto duradouro e não ocasional. A vontade política em criar uma estrutura perene, e não de maneira precipitada no calor de escândalos, aliada aos resultados práticos atingidos por estas instituições ao longo do tempo, como o desbaratamento de esquemas de corrupção notórios (SMILOV, 2010, p. 75), pode servir como antídoto para o desgaste e desmantelamento ocasionado por uma possível ineficiência destas agências, submetidas a uma tarefa hercúlea.

Outra contribuição interessante no assunto e que segue a mesma linha de Sousa e Smilov, parte de Kuris (2014, p. 19). A partir de uma análise de experiências de países emergentes (Botsuana, Croácia, Gana, Indonésia, Letônia, Lituânia, Ilhas Maurício e Eslovênia), o pesquisador concluiu que agências anticorrupção eficientes devem ter como base o apoio da opinião pública e serem capazes de realizar grandes feitos para manterem este suporte, podendo assim desencadear uma série de reformas e mudar a dinâmica de um ambiente corrupto.

Speville (2008, p. 02-06) enumera algumas falhas graves que resultam na ineficiência de uma agência anticorrupção. Podem ser citadas falta de vontade política ou sua interferência; delegar o controle da corrupção a órgão não especializado; falta de recursos; desconhecimento da natureza da corrupção e os benefícios em combatê-la; expectativas irreais que podem causar frustrações, como a ideia que é possível erradicar totalmente a corrupção (DOIG; WATT; WILLIAMS, 2007, p. 258); falta de planejamento e estratégia, de modo a envolver não apenas o processamento e punição de práticas corruptas, mas criar mecanismos de desincentivo que diminuíam as oportunidades para a corrupção proliferar; falta de envolvimento da população; falta de transparência; e falta de cooperação com outros órgãos da administração pública e estrangeiros. Por fim, menciona que em uma situação na qual a própria agência torna-se corrupta, a única alternativa é o encerramento do projeto.

O mais próximo de uma agência anticorrupção brasileira é a experiência da Controladoria-Geral da União (CGU). Em 2001, o governo federal criou a Corregedoria-Geral da União, que possuía o propósito de administrar políticas anticorrupção no setor público (Medida Provisória nº 2.143-31). Em 2002, foi agregada a função de controle interno, passando a realizar auditorias na execução dos programas do governo federal com objetivo de avaliar os resultados. Na mesma ocasião, foi atribuída a função de ouvidoria-geral, tornando-se responsável por receber não apenas denúncia de corrupção, mas qualquer feedback da sociedade em relação à 
atuação do governo federal. Em 2003, seu nome foi alterado para Controladoria-Geral da União (Lei Federal no $10.683 / 2003)$.

Atualmente, a CGU mantém as funções de órgão central do sistema de controle interno do poder executivo federal (SANTOS, 2009, p. 104) e de assessoramento ao Presidente da República em assuntos relativos à defesa do patrimônio público, gestão transparente e prevenção à corrupção. Com um rol de atribuições de grande abrangência, a CGU acaba por acumular uma série de funções díspares, como auditoria, fiscalização e avaliação dos programas do governo, monitoramento dos sorteios públicos (como a loteria federal), inspeção e condução processos administrativos disciplinares contra servidores públicos do governo federal e gestão de políticas de transparência pública que envolvem acesso à informação, supervisão das ouvidorias federais, entre outras atribuições.

De acordo com a classificação proposta por Sousa (2008), a CGU pode ser enquadrada como "Instituição Especializada com Múltiplas Competências". Como a CGU atua exclusivamente no âmbito do poder executivo federal, esta iniciativa tem sido replicada em alguns Estados e Municípios brasileiros, que criaram suas próprias Controladorias.

A CGU tem assumido o protagonismo na propositura de novos mecanismos legislativos de controle da corrupção. Sua atuação foi destacada nas recentes reformas legislativas que envolveram a criação da Lei da Transparência Pública (Lei Federal nº 12.527/2011), Lei de Conflito de Interesses no Governo Federal (Lei Federal no 12.813/2013) e da Lei Anticorrupção Empresarial (Lei Federal no 12.846/2013). Também é digno de nota que a CGU é o órgão que tem representado o governo brasileiro externamente nos fóruns internacionais anticorrupção, participando ativamente dos processos de avaliação da OEA, OCDE e ONU.

Apesar de contar com uma estrutura de certa forma robusta, uma vez que possui cerca de 2.500 servidores (CONTROLADORIA-GERAL DA UNIÃO, 2014), a maior parte ingressantes por meio de concurso público, e um orçamento de cerca de 600 milhões de reais anuais, a CGU tem enfrentado alguns problemas que podem comprometer o seu funcionamento. A aglutinação de funções variadas pode sobrecarregar o órgão e ocasionar o desvio da função de gestor de políticas anticorrupção, de acordo com o apontamento de Speville (2008, p. 04) e Santos (2009, p. 104-105). Deve também ser ressaltado que a Controladoria não parece gozar de total independência para o exercício de seu mandato, da mesma forma que outras importantes instituições brasileiras, como o Ministério Público e o Poder Judiciário, ou até mesmo em comparação com experiências estrangeiras congêneres.

O complexo sistema federativo brasileiro coloca a CGU como parte integrante do Poder Executivo federal e com status de Ministério, submetendo-se totalmente ao comando da Presidência da República. Observase que o cargo de diretor da agência é de confiança, de livre nomeação e exoneração do Presidente, não havendo 
qualquer tipo de participação do Poder Legislativo na escolha ou proteção para o exercício de seu mandato. Esta inserção da CGU na estrutura governamental federal impede que atue diretamente em causas envolvendo outras unidades da federação brasileira (Estados, Distrito Federal e Municípios), a não ser que haja ameaça ao patrimônio público federal. Neste contexto, os demais entes federativos ficam desguarnecidos, a não ser que criem, por iniciativa própria, suas agências anticorrupção. Por fim, são alarmantes as recentes notícias de que o orçamento da CGU teria sido reduzido bruscamente entre 2013 e 2014, em cerca de 26\% (CONTROLADORIA-GERAL DA UNIÃO, 2014), passando a enfrentar dificuldades em pagar suas despesas mais básicas (MINISTRO, 2014).

É preciso estabelecer com clareza quais são as funções da CGU no controle da corrupção no âmbito nacional. Recentemente, com o advento da Lei Federal no 12.846/2013 (Lei Anticorrupção Empresarial), a CGU assumiu a atribuição de conduzir processos administrativos de responsabilização das empresas pelo suborno de agentes públicos federais, sendo capaz de aplicar multa correspondente ao valor de $20 \%$ sobre o faturamento bruto anual da organização empresária. Apesar da nova importante atribuição, sua estrutura continua inalterada, permanecendo vulnerável às pressões políticas. Também é digno de nota que dentro do sistema federativo brasileiro, nos casos envolvendo a referida lei, a atuação da CGU continua sendo limitada aos assuntos de interesse federal, delegando aos Estados e Municípios o processamento administrativo de empresas envolvidas em suborno de agentes públicos estaduais e municipais, respectivamente. Muitos entes federativos não possuem qualquer estrutura anticorrupção, o que pode prejudicar a aplicação efetiva da legislação nestas esferas.

O acúmulo de funções díspares da CGU pode representar um obstáculo para a especialização. O próprio nome escolhido para o órgão - "controladoria" - representa pouco o motivo de sua criação e sua função principal. Uma possibilidade é a cisão em dois órgãos, um responsável pelo controle interno na administração pública federal e demais questões residuais atualmente atribuídas à CGU, e outro especializado exclusivamente no fenômeno da corrupção. Esta "Comissão Nacional Anticorrupção" brasileira deveria desenvolver maior independência dentro da estrutura estatal para exercer o seu mandato - o que pressupõe, dentre outros requisitos, deixar de ser um órgão auxiliar da Presidência da República e assumir uma posição de autonomia administrativa e financeira, como o status de autarquia. Inspirado em outras experiências internacionais bem-sucedidas, as funções desta instituição, agora dotada de maior autonomia, compreenderão plenamente o tripé "investigação, prevenção e educação" do fenômeno da corrupção. Sugere-se que seja capaz de exercer seu mandato em todo o território nacional. 


\section{CONCLUSÃO}

Após todo o exposto, cumpre a apresentação de uma série de considerações finais acerca da matéria. Primeiramente, é importante salientar que as teorizações originadas num contexto de Guerra Fria (as quais podem ser qualificadas como sendo "ocidentais", eis que o trabalho se ateve quase que exclusivamente a tal contexto, sem ter se ocupado das possíveis observações atinentes à corrupção oriundos, em tal época, àquelas provenientes do chamado "bloco socialista") não viam como problemática a ocorrência da corrupção em países em desenvolvimento, a ponto de, até mesmo, haver manifestações acadêmicas que a consideravam benéfica em tais países. A necessidade de manter uma situação de bipolaridade geopolítica bem definida fazia com que as potências - EUA e países europeus, principalmente - mantivessem-se alinhadas com Estados em que a corrupção grassava.

O fim da bipolarização mundial e o advento da globalização, entretanto, fazem emergir a impossibilidade de alinhamento com as cleptocracias. Ademais, passa-se a expor que a corrupção não se trata de um problema apenas de países em desenvolvimento, mas sim, uma ocorrência comum em países considerados desenvolvidos. E esta guinada contextual repercute nas teorizações acerca do fenômeno da corrupção de modo bastante significativo.

A concretização na prática das teorias acerca da corrupção pode ser observada na criação de agências anticorrupção em vários países. Símbolos do compromisso dos governos com a intolerância a práticas espúrias, apesar de se apresentarem sob várias configurações, estas agências se caracterizam, geralmente, pela função e operação especializadas - a ponto de haver teorizações apontando que a multiplicidade de focos pode dificultar sua implementação. É notável, também, que o sucesso destas agências depende, primordialmente, da consolidação e da continuidade de regimes democráticos nos países em que são criadas e instaladas - sendo observável que apenas após o término de regimes ditatoriais e cleptocráticos os governos dos países estudados (mesmo em contextos bastante complexos e desfavoráveis, tais como países africanos) conseguiram fazê-lo.

É possível, portanto, de modo preliminar, apontar dois requisitos para o sucesso de políticas anticorrupção: democratização substancial e especialização das agências criadas. Mas outros requisitos podem ser elencados após este estudo. O primeiro deles, independência de atuação em relação a eventuais interferências políticas. Como as agências podem ser redesenhadas ou obliteradas conforme a mudança de governos é preciso blindá-las às interferências deletérias das forças políticas, o que prejudica a sua atuação em longo prazo.

Em segundo lugar, o desenvolvimento de estruturas de cooperação para com outros órgãos, entes e instâncias (numa perspectiva de macro-observação) e de capacidades interdisciplinares de seus recursos humanos (em uma perspectiva de micro-observação) acaba com situações de isolamento e de preocupação apenas com formalismos da sua atuação. Isto se coaduna com uma necessidade de criação de agências complexas para o 
contexto complexo da globalização, em que a linearidade de atuação e a territorialidade de compreensão são superadas por qualquer operação corrupta que ultrapasse os limites do Estado-nação - que são cada vez mais comuns numa sociedade mundial que se comunica em rede, cuja economia é caracterizada por um capital volátil de atuação transnacional e possibilidades (velocidade e eficiência) de comunicação que superam em muito (e há muito) os localismos.

Em terceiro lugar, deve-se atentar para uma postura multitudinal e multifocal destas agências (o que não é necessariamente contrário à sua especialização): em outras palavras, estas agências devem assumir caráteres punitivos e preventivos; técnicos e científicos; de atuação independente, mas que se coadunem com seu suporte da opinião pública. Estes requisitos devem, aliás, corresponder a objetivos de transparência e perenidade das políticas virtualizadas em agências anticorrupção, pois o risco de que possam vir a ter sua atuação encerrada em razão de flutuações dos interesses políticos, ou até mesmo corrompida internamente (algo que pode vir a decorrer de um certo "efeito de cortina de fumaça" que as atuações sigilosas podem vir a mascarar) podem vir a colocar em risco sua própria existência.

Estas lições podem vir a corroborar com o desenvolvimento de políticas anticorrupção proficuas no Brasil. É claro que a simples implantação daquilo que foi bem sucedido em outros contextos de modo direto e não ponderado pode ser prejudicial (representando dispêndios excessivos em práticas desnecessárias ou, até mesmo, impossíveis); mas a comparação entre o que já se pratica no Brasil e aquilo que se tem de experiências em outros locais e épocas pode vir a fomentar estudos reflexivos, de aprendizado (e não mera cópia). Assim, é possível afirmar que se confirma a hipótese inicial para o problema de pesquisa apresentado - de que o estudo dos modelos anticorrupção utilizados por diversos países, em seus contextos histórico-geográficos e institucionais específicos, pode ser útil para a renovação e reestruturação do sistema jurídico-político brasileiro nesta área. Isto, porém, sem deixar de atentar para o fato de que mais pesquisas - tanto de ocorrências em outros países quanto daquilo que aqui se observa - são necessárias para a construção de um regime anticorrupção efetivo no contexto brasileiro.

\section{ANTI-CORRUPTION AGENCIES AND PUBLIC ADMINISTRATION: A COMPARATIVE PERSPECTIVE BETWEEN BRAZIL AND OTHER COUNTRIES}

\section{Abstract}

This paper aims to compare and to characterize various ways through which prosecution and prevention of corruption has been sought in several countries. Its research problem was: under what conditions the knowledge produced about corruption in public sphere (on anti-corruption agencies, especially) can foster better performances to the organs and entities of the Public Administration that are occupied with this incumbency? Its 
hypothesis suggests that the study of anti-corruption models used by different countries, in their historical, geographical and institutional specific contexts, can be helpful to the renewal and restructuring of the Brazilian legal and political systems in this area.

Keywords: public corruption; anti-corruption agencies; Public Administration.

\section{REFERÊNCIAS BIBLIOGRÁFICAS}

ANGELI, Alzira Ester. A Visão Geral das Agências Norte-americanas contra Corrupção numa Análise Comparativa com a Controladoria-Geral da União. Revista da CGU, Brasília, v. 7, p. 79-95, 2009.

BOBBIO, Noberto; MATTEUCCI, Nicola; PASQUINO, Gianfranco. Dicionário de política. 11 ed. Brasília: Universidade de Brasília, 1998.

COEHN, Paul H.; BURRELL, Peter; COGMAN, Susannah. UK Anti-Corruption Law. In: COEHN, Paul H.; MARRIOTT, Arthur (Org.). International Corruption. London: Sweet and Maxwell, 2010. p. 01-44.

CONTROLADORIA-GERAL DA UNIÃO. Portal Transparência Pública. Brasília, 2014. Disponível em: http://www3.transparencia.gov.br/TransparenciaPublica/jsp/execucao/execucaoPorProgGoverno.jsf. Acesso em: 01 nov. 2014.

DAMATTA, Roberto. O Que Faz o brasil, Brasil? Rio de Janeiro: Rocco, 1986.

DOIG, Alan; WATT, David; WILLIAMS, Robert. Hands-on or Hands-off? Anti-corruption Agencies in Action, Donor Expectations, and a good enough reality. Public Administration and Development, Hoboken, v. 26, p. 163 172, 2006.

Why do Developing Country Anti-Corruption Commissions Fail to Deal with Corruption? Understanding the Three Dilemmas of Organisational Development, Performance Expectation, and Donor and Government Cycles. Public Administration and Development, Hoboken, v. 26, p. 251-259, 2007.

ELLIOTT, Kimberly Ann. A Corrupção como um Problema de Legislação Internacional: Recapitulação e Recomendações. In: ELLIOTT, Kimberly Ann (Org). A Corrupção e a Economia Global. Brasília: Universidade de Brasília, 2002. p. 255-339.

FAORO, Raymundo. Os Donos do Poder: formação do patronato político brasileiro. 3 ed. rev. 8. reimpressão. São Paulo: Globo, 2001.

GLYNN, Patrick; KOBRIN, Stephen; NAÍM, Moises. A Globalização da Corrupção. In: ELLIOTT, Kimberly Ann (Org.). A Corrupção e a Economia Global. Brasília: Universidade de Brasília, 2002. p. 27-58.

HEILBRUNN, John R. Anti-Corruption Commissions: Panacea or Real Medicine to Fight Corruption? Washington, D. C.: Word Bank Institute, 2004.

HEIMANN, Fritz F. O Combate à Corrupção Internacional: o Papel da Comunidade Comercial. In: ELLIOTT, Kimberly Ann (Org.). A Corrupção e a Economia Global. Brasília: Universidade de Brasília, 2002.p. 219-240. 
HUNTINGTON, Samuel P. Political Order in Changing Societies. New York: Yale University Press, 1968.

KAUFMANN, Daniel. Six Questions on the Cost of Corruption with World Bank Institute Global Governance Daniel Kaufmann. 1999. Disponível em: http:/ / go.worldbank.org/KQH743GKF1. Acesso em: 25 out. 2014.

KENNEDY, David. The International Anti-Corruption Campaign. Connecticut Journal of International Law, Hartford, v. 14, p. 455-465, 1999.

KLITGAARD, Robert. A Corrupção sob Controle. Rio de Janeiro: Jorge Zahar Editor, 1994.

KLITGAARD, Robert; MACLEAN-ABAROA, Ronald; PARRIS, H. Lindsey. Corrupt Cities: A Practical Guide to Cure and Prevention. Washington, D. C.: World Bank Publications, 2000.

KURIS, Gabriel. From Underdogs to Watchdogs: How Anti-corruption Agencies Can Hold Off Potent Adversaries. Innovations for Successful Societies: Princeton University. [S. 1.], 2014. Disponível em: http://www.princeton.edu/successfulsocieties/content/focusareas/AC/ policynotes/view.xml?id=236. Acesso em: 21 set. 2014 .

LEAL, Victor Nunes. Coronelismo, Enxada e Voto. 3 ed. 3 reimpressão. Rio de Janeiro: Editora Nova Fronteira. 1997.

LEFF, Nathaniel H. Economic Development Through Bureaucratic Corruption. American Behavior Scientist, Thousand Oaks, v. 8, n. 3, p.8-14, 1964.

LUHMANN, Niklas. La Sociedad de la Sociedad. Tradução de Javier Torres Nafarrate. México: Herder, 2007.

MANZETTI, Luigi. Market Reforms Without Transparency. In: TULCHIN, Joseph S.; ESPACH, Ralph H (Org.). Combating Corruption in Latin America. Washington, D. C. : Woodrow Wilson Center Press, 2000. p. 130-172.

MAURO, Paolo. Os Efeitos da Corrupção sobre o Crescimento, Investimentos e Gastos do Governo: Uma Análise de Países Representativos. In: ELLIOTT, Kimberly Ann (Org.). A Corrupção e a Economia Global. Brasília: Universidade de Brasília, 2002. p. 135-168.

MINISTRO da CGU afirma que enfrenta situação de 'penúria orçamentária'. Portal G1. [S. 1.], 2014. Disponível em: http://g1.globo.com/politica/noticia/2014/09/ministro-afirma-que-cgu-enfrenta-situacao-de-penuriaorcamentaria.html. Acesso em: 01 nov. 2014.

MONTEIRO, Fernando Mendes. Anti-Corruption Agencies: Solution or Modern Panacea? Lessons for Ongoing Experiences. Minerva Program: George Washington University. Washington, D. C., 2014. Disponível em: http://www.gwu.edu/ ibi/pesquisa.html\#corruption. Acesso em: 28 set. 2014.

MORRIS, Stephen D.; BLAKE, Charles H. Political and Analytical Challenges of Corruption in Latin America. In: MORRIS, Stephen D.; BLAKE, Charles H (Org.). Corruption and Democracy in Latin America. University of Pittsburgh Press: Pittsburgh, 2009. p. 01-22.

NEVES, Marcelo. Transconstitucionalismo. São Paulo WMF Martins Fontes, 2009. 
NOONAN JUNIOR, John T. Subornos. Rio de Janeiro: Bertrand Brasil, 1989.

NORTH, Douglass Cecil. Institutions. The Journal of Economic Perspectives, Nashville, v. 5, n. 1, p. 97-112, 2001.

NYE JR, Joseph S. Corruption and Political Development: A Cost-Benefit Analysis. The American Political Science Review, Cambridge, v. 61, n. 2, p. 417-427, 1967.

ORGANISATION FOR ECONOMIC CO-OPERATION AND DEVELOPMENT (OECD). Specialised Anti-Corruption Institutions: Review of Models. Paris: OECD, 2008.

POPE, Jeremy; VOGL, Frank. Making Anti-corruption Agencies More Effective. Finance \& Development, Washington, D. C., v. 37, n. 02, p. 01-10, 2000.

QUAH, Jon S. T. Controlling Corruption in City-States: A Comparative Study of Hong Kong and Singapore. Crime, Law and Social Change, Berlin, v. 22, p. 391-414, 1995.

ROSE-ACKERMAN, Susan. A Economia Política da Corrupção. In: ELLIOTT, Kimberly Ann (org). A Corrupção e a Economia Global. Brasília: Universidade de Brasília, 2002.p. 59-102.

SANTOS, Romualdo Anselmo dos. Institucionalização dos Mecanismos Anticorrupção: da Retórica ao Resultado. Revista da CGU, Brasília, n. 6, p. 85-113, 2009.

SHLEIFER, Andrei; VISHNY, Robert W. Corruption. The Quarterly Journal of Economics, Oxford, v. 108, n. 3, p. 599-617, 1993.

SMILOV, Daniel. Anti-corruption Agencies: Expressive, Constructivist and Strategic uses. Crime, Law and Social Change, Berlin, v. 53, n. 1, p. 05-22, 2010.

SOUSA, Luís de. Anti-corruption Agencies: Between Empowerment and Irrelevance. Crime, Law and Social Change, Berlin, v. 53, n. 1, p. 05-22, 2010.

As Agências Anticorrupção como Peças Centrais de um Sistema de Integridade. Revista da CGU, Brasília, n. 4, p. 20-45, 2008.

SPECK, Bruno W. O Controle da Corrupção como um Desafio Transnacional. In: SPECK, Bruno W. (Org.) Caminhos de Transparência: Análise dos Componentes de um Sistema Nacional de Integridade. Campinas: UNICAMP, 2002.p. 445-478.

SPEVILLE, Bertrand de. Failing Anti-corruption Agencies - Causes and Cures. [S. 1.], 2008. Disponível em: http://ancorage-net.org/index.jsp?page=documents\&id=46. Acesso em: 21 set. 2014.

TANZI, Vito. Corruption around the world: Causes, consequences, scope and cures. IMF Staff Papers, Washington, D. C., v. 45, n. 4, p. 559-594, 1998.

TAYLOR, Matthew M.; POWER, Timothy J. Introduction: Accountability Institutions and Political Corruption in Brazil. In: TAYLOR, Matthew M.; POWER, Timothy J (Org.). Corruption and Democracy in Brazil: the Struggle for Accountability. Notre Dame: University of Notre Dame Press, 201 1.p. 01-28. 
TRANSPARENCY INTERNATIONAL. Global Corruption Barometer 2013. Berlin: Transparency International, 2013.

TULCHIN, Joseph S.; ESPACH, Ralph H. Introduction. In: TULCHIN, Joseph S.; ESPACH, Ralph H (Org.). Combating Corruption in Latin America. Washington, D. C.: Woodrow Wilson Center Press, 2000. p. 01-12.

UNITED NATIONS OFFICE ON DRUGS AND CRIME (UNODC). Country Profiles. [S. 1.], 2014. Disponível em: https://www.unodc.org/unodc/en/treaties/CAC/country-profile/index.html. Acesso em: 12 nov. 2014.

WEI, Shang-Jin. Corruption and Globalization. Washington, D. C., 2001. Disponível em: http://www.brookings.edu/papers/2001/04corruption_wei.aspx. Acesso em: 11 dez. 2011.

WORLD BANK. Anti-corruption Authorities. Washington, D. C., 2014. Disponível em: http://www.acauthorities. org. Acesso em: 01 jul. 2014.

Trabalho enviado em 15 de junho de 2015.

Aceito em 07 de agosto de 2015. 